\title{
NEGOCIACIÓN COLECTIVA Y PROLONGACIÓN DE LA VIDA ACTIVA DEL TRABAJADOR: REFLEXIONES A PARTIR DE LA EXPERIENGIA ESPAÑOLA Y FRANGESA*
}

\author{
COLLECTIVE BARGAINING AND EXTENSION OF THE ACTIVE \\ LIFE OF THE WORKER: REFLECTIONS FROM THE SPANISH \\ AND FRENCH EXPERIENCE
}

\section{Fernando ELORZA GUERRERO**}

RESUMEN: La prolongación de la vida activa de los trabajadores de edad avanzada constituye una de las políticas sociales centrales de la Unión Europea en relación con la garantía futura del Estado de bienestar en Europa. En este sentido, el presente artículo constituye una reflexión sobre el papel futuro que la autonomía colectiva, y en definitiva los representantes de los trabajadores y empresarios, ha de desempeñar en esta materia, partiendo de la experiencia existente al respecto en España y Francia. Constatada la existencia de un largo camino por recorrer, particularmente por lo que respecta al desarrollo de dinámicas de nego-
ABSTRACT: The prolongation of the active life of older workers is one of the central social policies of the European Union in relation to the security in the future of the Welfare State in Europe. In this regard, this article is a reflection on the future role that the collective autonomy, and ultimately the workers' representatives and employers, has to play in this area, on the basis of existing experience in Spain and France. Finding the existence of a long way to go, particularly with regard to the development of intergenerational dynamics of negotiation, the author pleads for the development of negotiating practices inclusive of the labour activity of young and older workers that takes into account the positive values that each group can contribute to the develop-

* Artículo recibido el 1 de agosto de 2016 y aceptado para su publicación el 16 de enero de 2017.

** Profesor titular de derecho del trabajo y de la seguridad social en la Universidad Pablo de Olavide, Sevilla (España).Email:felogue@upo.es.

Estudio realizado en el marco del Proyecto I+D+I del Ministerio de Ciencia e Innovación DER201 1-28907: "El futuro de la negociación colectiva en materia de jubilación".

El autor quiere agradecer a la Universidad Católica de Lyon (Francia) las facilidades dadas para profundizar en el análisis del ordenamiento jurídico laboral francés en el marco de una estancia investigadora desarrollada en marzo de 2015.

Boletín Mexicano de Derecho Comparado nueva serie, año XLX, núm. 149, mayo-agosto de 2017, pp. 673-705

D. R. (C) 2017. UNAM, Instituto de Investigaciones Jurídicas. 
Esta revista forma parte del acervo de la Biblioteca Jurídica Virtual del Instituto de Investigaciones Jurídicas de la UNAM

ciación intergeneracional, el autor aboga por el desarrollo de prácticas negociadoras integradoras de la actividad laboral de los trabajadores jóvenes y de edad avanzada, que tenga en cuenta los valores positivos que cada colectivo puede aportar al desarrollo de las empresas. No obstante, se considera que la acción de la autonomía colectiva en este ámbito debe acompañarse de un tratamiento legal más específico de la edad avanzada del trabajador, como factor con incidencia en el empleo y la relación de trabajo, que respalde la acción de aquélla.

Palabras clave: negociación colectiva, trabajadores de edad avanzada, empleo, prolongación de la vida activa, seguridad social. ment of intergenerational dynamics of negotiation, the author pleads for the development of negotiating practices inclusive of the labour activity of young and older workers that takes into account the positive values that each group can contribute to the development of the enterprises. However, it is considered that the action of the collective autonomy in this area must be accompanied by a more specific legal treatment of the advanced age of the worker as a factor with impact on employment and the working relationship that support the action of that.

Keywords: Collective bargaining, older workers, employment, prolongation active life, social security.

SUMARIO: I. Introducción. II. La incorporación a los ordenamientos jurídicos español y francés de los planteamientos comunitarios a favor de los trabajadores de edad avanzada. III. La prolongación de la vida activa del trabajador de edad avanzada como objeto de la negociación colectiva. IV. Sobre la necesidad de un tratamiento específico legal de la edad avanzada como factor que incide en el empleo y en la relación de trabajo. V. Reflexión final. VI. Bibliografia.

\section{INTRODUCGIÓN}

La prolongación de la vida activa de los trabajadores, y particularmente de aquellos que alcanzan ya una cierta edad avanzada, ha constituido una preocupación de la Unión Europea desde hace años. No en vano, desde que viera la luz la Resolución sobre el empleo de los trabajadores en edad madura de 1995, múltiples han sido los consejos de la Unión Europea que, con mayor o menor detalle, se han ocupado y preocupado de esta cuestión. Sin ánimo de exhaustividad, qué duda cabe que el Plan general para el empleo, aprobado en el Consejo de Lisboa de 2000, constituyó un punto de inflexión en relación con tales políticas, si bien el mismo contempló un objetivo que con el tiempo se demostró excesivamente ambicioso, como fue 
Esta revista forma parte del acervo de la Biblioteca Jurídica Virtual del Instituto de Investigaciones Jurídicas de la UNAM

que para 2010 la tasa de empleo total de los trabajadores entre 55 y 64 años alcanzara un $50 \%$.

En años posteriores, hemos conocido la formulación de una serie de líneas de actuación que hoy día no son bastante familiares, pero que entonces constituyeron una absoluta novedad. Así, en 2002, en el Consejo de Barcelona se señaló la oportunidad, y necesidad, de aumentar la edad de jubilación en unos cinco años antes de 2010. Igualmente, en 2005, y una vez que resulta evidente el incumplimiento de los objetivos marcados por la Estrategia de Lisboa, en el seno de la Unión se aprobaron los "Orientamientos Integrales para el Crecimiento y el Empleo", documento en el que se planteaba la necesidad tanto de modernizar - en cuanto poner al día - los sistemas de pensiones y de sanidad, como adoptar medidas que desincentivaran la prejubilación.

Como trasfondo de esta actuación comunitaria ha de tenerse en cuenta que para la Comisión Europea "no hay pruebas empíricas de que los trabajadores más jóvenes y los de más edad sean intercambiables", ${ }^{1}$ de tal forma que la entrada de uno y otro grupo poblacional no coinciden necesariamente en los mismos sectores, con lo que no necesariamente la permanencia de trabajadores maduros en activo tiene que suponer un obstáculo insalvable para la incorporación de los jóvenes al mercado de trabajo. Esta forma de ver las cosas ha impregnado, e impregna, la política comunitaria sobre envejecimiento activo de los últimos veinte años, y explica la acción comunitaria en relación con un mercado de trabajo, el europeo, donde el trabajo comienza a ser escaso, entre otros factores por el avance tecnológico - internet, entre otros factores a considerar-. De hecho, iniciada la presente crisis económica, allá por 2009, la Comisión veía la cuestión, que interesa en este momento, de la siguiente manera: la "prioridad deberá ser garantizar que los jóvenes que no logren entrar en el mercado laboral no inicien una vida de dependencia permanente de las prestaciones de desempleo, y lograr que los trabajadores de más edad que hayan sido despedidos puedan volver a ocupar un puesto de trabajo una vez que haya mejorado la situación del mercado laboral". ${ }^{2}$

1 Comunicación de la Comisión "Aumentar el empleo de los trabajadores de más edad y retrasar su salida del mercado de trabajo", COM (2004) 146 final, p. 3.

2 Comunicación de la Comisión "Abordar los efectos del envejecimiento de la población de la UE (Informe de 200 sobre el envejecimiento demográfico)", COM (2009) 180 final, p. 8. 
Esta revista forma parte del acervo de la Biblioteca Jurídica Virtual del Instituto de Investigaciones Jurídicas de la UNAM www.juridicas.unam. $\mathrm{mx}$

DOI: http://dx.doi.org/10.22201/iij.24484873e.2017.149.11354

En esta línea, recordemos que en 2006 el Consejo dictó una Decisión, la 2006/544/CE, del 18 de julio, ${ }^{3}$ en la que básicamente se planteaba, por un lado la necesidad de atraer y retener el mayor número de personas posibles en el mercado de trabajo - conscientes por tanto de la señalada previsible escasez del trabajo en un futuro-, al tiempo que se modernizaban los sistemas de protección social; por otro, la mejora de la capacidad de adaptación de los trabajadores y empresas, y, finalmente, la necesidad de invertir más en capital humano, mejorando para ello la educación y las competencias de los trabajadores. Estas directrices pervivieron en el tiempo como parte de la "Estrategia para el empleo 20052008".

Años después, la Comisión Europea publicó, en 2012, el "Libro Blanco 2012: Una Agenda para unas pensiones adecuadas, seguras y sostenibles". ${ }^{4}$ Dicho libro constituye en estos momentos el principal documento estratégico que orienta la acción de la UE y de sus Estados miembros en materia de pensiones. En el mismo se plantea, entre otros aspectos, que la adecuación y sostenibilidad de las pensiones pasa por incrementar la edad de jubilación, prolongar la vida activa de los trabajadores, y, finalmente, incrementar la participación de los trabajadores de más edad en el mercado de trabajo. Pues bien, la estrategia comunitaria en favor de la prolongación de la vida activa de los trabajadores ha generado, como no podía ser de otra manera, una significativa acción legislativa de los Estados miembros de la Unión, particularmente intensa en estos últimos años. A la comparación de la actuación legislativa en España y Francia, y al papel otorgado a la negociación colectiva dedicamos las próximas páginas. ${ }^{5}$ No obstante, se ha de advertir desde un principio que la actuación del legislador en estos años en ambos países, y como en algún caso ya se ha

3 Las directrices de esta Decisión básicamente mantenían la fijadas por la Decisión del Consejo 2005/600/CE, del 12 de julio de 2005.

4 COM (2012) 55 final. Documento que fue completado por otros posteriores, como el "Informe de envejecimiento 2012. Proyecciones económicas y presupuestarias para los 2 Estados miembro de la UE (2010-2060)", o el titulado "Adecuación de las pensiones en la UE 2010-2015".

5 Sobre la influencia de las políticas comunitarias en las reformas de seguridad social francesas, y en particular en la de 2003, de especial significación a los efectos que aquí interesan, véase Coursier, Philippe, "La réforme française des retraites et l'Union européene", Droit Social, núm. 11 (monográfico: La réforme des retraites. Loi du 21 août 2003), pp. 983 y ss. 
Esta revista forma parte del acervo de la Biblioteca Jurídica Virtual del Instituto de Investigaciones Jurídicas de la UNAM

señalado, se ha centrado fundamentalmente en: a) endurecer el régimen de la jubilación; $b$ ) establecer incentivos económicos que fomenten la permanencia como activos de dichos trabajadores, y $c$ ) atender de forma más intensa a la regulación de los periodos finales de la carrera profesional de los trabajadores. ${ }^{6}$ En todo caso, la actuación legislativa registra diferencias notables, como se comprobará, por lo que respecta al enfoque que se hace de la cuestión en cada caso y los conceptos manejados.

\section{LA INCORPORACIÓN A LOS ORDENAMIENTOS JURÍDICOS ESPAÑOL Y FRANGÉS DE LOS PLANTEAMIENTOS COMUNITARIOS A FAVOR DE LOS TRABAJADORES DE EDAD AVANZADA}

\section{La experiencia española}

Sin ánimo de remontarme en el tiempo a las primeras actuaciones en esta materia, parece claro que la acción legislativa española al respecto se ha intensificado en España a partir de 2011, y particularmente tras la aprobación del Informe de Evaluación y Reforma del Pacto de Toledo, el 25 de enero de 2011, y el posterior, y conocido, Acuerdo Social y Económico para el Crecimiento, el Empleo y la Garantía de las Pensiones, del 2 de febrero de 2011 (ASE 2011).

En el caso del informe, en él ya se apuntaban una serie de claves que han marcado, en distinta medida, la acción del Poder Legislativo. Así, la comisión del Pacto de Toledo, al abordar la cuestión de la edad de jubilación, realizó una declaración de principios en favor "de la prolongación de la vida laboral de los ciudadanos como un objetivo necesario y deseable"7 - directriz 12-. A tales efectos, planteaba las siguientes medidas: a) la modificación del régimen jurídico de la jubilación, otorgando

6 Desbarats, Isabelle y Esteban Legarreta, Ricardo, "Dispositivos de protección social que incentivan el mantenimiento en actividad de los trabajadores maduros: una tendencia análoga en Francia y España”, en AA.VV, La protección del empleo de los trabajadores de edad: una perspectiva franco-española, Valencia, Tirant lo Blanch, 2013, p. 183.

7 Como se señala en el propio informe, la idea es "promover un nuevo marco legal de la edad de jubilación más basado en la flexibilidad y la gradualidad y en el mantenimiento de estímulos a la prolongación de la vida laboral y en un esquema razonable de posibilidades de jubilación anticipada, en el que prime que la cuantía de la pensión a percibir dependa más del número de años cotizados a lo largo de la vida de las personas, 
Esta revista forma parte del acervo de la Biblioteca Jurídica Virtual del Instituto de Investigaciones Jurídicas de la UNAM

mayor relevancia a la carrera de cotización a la hora de fijar la cuantía de la pensión; $b$ ) la reforma del régimen de la jubilación anticipada, de forma que se reserve la misma a los trabajadores con largas carreras de jubilación - excepciona el supuesto de ciertos colectivos (actividades penosas, personas con grado de discapacidad...) -; c) la reconsideración de las once fórmulas de acceso a la pensión de jubilación, desde la perspectiva del enfoque asumido por la Comisión del Pacto en esta ocasión; d) la incentivación de la prolongación de la vida laboral, mediante "la adaptación y mejora de cuantos incentivos sociales, fiscales y laborales sean posibles para fomentar la permanencia de los trabajadores en activo" - se cita expresamente posibilitar que las cotizaciones que darían lugar a una pensión superior al tope máximo den lugar a un incremento mensual de la pensión final-; e) una mejor coordinación entre la legislación laboral y de seguridad social con relación al objetivo de ocupación de los mayores - y en concreto, aspectos como las pensiones de incapacidad y su conexión con el empleo, el contrato de relevo, la cotización del empleo a tiempo parcial o las entradas y salidas del empleo de los pensionistas-; $f$ ) una mayor permeabilidad entre la vida activa y pasiva que permita e incremente la coexistencia del salario y la pensión; $g$ ) el combate contra la discriminación por edad, restringiendo al máximo el abandono prematuro de la vida laboral (jubilación obligatoria), y $h$ ) la adopción de políticas activas de empleo orientadas a la recolocación de las personas de más edad y a su mantenimiento en situación activa.

Por lo que respecta al ASE 2011, hay que comenzar señalando que el mismo supone el retorno al ámbito del consenso, en el marco del diálogo social, en materia de reforma del régimen de seguridad social, retomando con ello la senda abandonada en 2007. ${ }^{8}$ Acuerdo multifacético, como sabemos, que en su parte II, y bajo el título "Acuerdo para la reforma y el fortalecimiento del sistema público de pensiones", asumió los principales postulados del informe de la comisión del Pacto de Toledo antes indicados. Con todo, lo más significativo del mismo fue el traslado de sus contenidos al ámbito legal, en una clara manifestación de legislación negocia-

de su esperanza de vida en el momento de la jubilación y de su capacidad de elegir en qué momento abandonan el mercado de trabajo, que de otros factores".

8 Sobre esta cuestión véase Panizo Robles, José Antonio, "Dos décadas de reformas de la seguridad social: del Pacto de Toledo de 1995 al Acuerdo Social y Económico de 2011 ”, Revista de Trabajo y seguridad social, CEF, núm. 336, 2011, pp. 77 y ss. 
Esta revista forma parte del acervo de la Biblioteca Jurídica Virtual del Instituto de Investigaciones Jurídicas de la UNAM

da, por la Ley 27/2011, del 1o. de agosto, sobre actualización, adecuación y modernización del sistema de seguridad social. ${ }^{9}$

La mencionada ley centró sobre todo sus esfuerzos en: $\left.{ }^{10} a\right)$ establecer una nueva edad de jubilación, con la intención de fijarla en 2020 en 67 años; b) reformar la prestación económica de la jubilación, incidiendo sobre las reglas de cálculo de pensión - aunque sin incidir en la ponderación de la esperanza de vida, cuestión que legislativamente no se abordará hasta $2013^{11}$ - y c) fijar un nuevo régimen de las jubilaciones anticipadas, tanto totales, como parciales.

Sin embargo, sabido es que en esta ley no se realizó planteamiento alguno en cuanto a las políticas de empleo a aplicar respecto a los trabajadores de edad avanzada, ya que el propio Acuerdo encomendaba al gobierno, "previa consulta y negociación con las organizaciones empresariales y sindicales firmantes" del mismo, la elaboración de una estrategia global de empleo de este colectivo. ${ }^{12}$ En cumplimiento de este compromiso, se dictó la Resolución del 14 de noviembre de 2011 de la Secretaría de Estado de Empleo, por la que se publica el acuerdo del Consejo de Ministros que aprueba la Estrategia Global para el Empleo de los Trabajadores y las Trabajadoras de Más Edad 2012-2014 (estrategia 55 y más). ${ }^{13}$

9 No en vano la ley, en su exposición de motivos, señala que la misma "tiene como finalidad llevar al ordenamiento de la seguridad social los compromisos recogidos en el Acuerdo social y económico mencionado, así como incorporar algunas de las recomendaciones reflejadas en la nueva reformulación del Pacto de Toledo".

10 Sobre esta ley, entre otros, remito al análisis en profundidad realizado por Tortuero Plaza, José Luis, La reforma de la jubilación. (Marco de referencia y Ley 27/2011, de 1 de agosto, sobre Actualización, Adecuación y Modernización del Sistema de la seguridad social), Madrid, Thomson-Reuters, 2011.

11 Cuando se dicta el Real Decreto-ley 5/2013, del 15 de marzo, de medidas para favorecer la continuidad de la vida laboral de los trabajadores de mayor edad y promover el envejecimiento activo, y particularmente la Ley 23/2013, del 23 de diciembre, reguladora del Factor de Sostenibilidad y del Índice de Revalorización del Sistema de Pensiones de la seguridad social, si bien y como sabemos, en el caso de esta última el denominado "factor de sostenibilidad" - elemento clave en la sostenibilidad futura del sistema de seguridad social-, no se aplicará hasta el 1o. de enero de 2019, y a las pensiones que se causen a partir de esa fecha.

12 Y que se convirtió en mandato legal en virtud de la D.A. 2a. del Real Decreto-ley 1/2011, del 11 de febrero, de medidas urgentes para promover la transición al empleo estable y la recualificación profesional de las personas desempleadas.

13 Previamente, y por tanto de forma separada, y no tematizada, el gobierno español aprobó el Real Decreto 1542/2011, del 31 de octubre, por el que se aprueba la Estrategia Española de Empleo 2012-2014. 
Esta revista forma parte del acervo de la Biblioteca Jurídica Virtual del Instituto de Investigaciones Jurídicas de la UNAM

De repente, por tanto, en 2011 observamos cómo el panorama jurídico en relación con el empleo de los trabajadores de edad avanzada cambia significativamente. En el origen de este nuevo escenario está el establecimiento de una nueva forma de interrelación entre las políticas de empleo y las de seguridad social, que sin duda viene inducido por los planteamientos comunitarios, antes referidos, en relación con el envejecimiento activo. ${ }^{14}$ Así, el proceso de reformas legales que se inicia con esta ley ha permitido, en pocos años, configurar la jubilación como una institución poliédrica, cuya única misión ya no es el aseguramiento de la sustitución de la renta ante una situación de necesidad, sino también sostener e inducir la actividad de los trabajadores más allá de la edad real de retiro, que en España se sitúa en torno a los 63.5 años. En forma inversa, en este caso parece claro que la política de empleo se coloca a partir de ahora "al servicio de la viabilidad futura de los sistema públicos de pensiones como una manera de hacer frente a sus problemas demográficos y financieros". ${ }^{15}$

Qué duda cabe que, a partir de esta norma legal, el legislador español muestra un especial interés, en línea con lo sugerido por los documentos comunitarios sobre envejecimiento activo, por poner la institución de la jubilación al servicio de la actividad del trabajador de edad avanzada. De tal manera que es en este momento cuando aquél cambia significativamente la perspectiva desde la que abordar el final de la carrera profesional de los trabajadores: ya no se trata tanto de establecer un marco jurídico que permita el tránsito de la vida activa a la situación de inactivo de forma suave o no traumática, sino que en adelante existe un interés legislativo, del que participan en gran medida los agentes sociales, todo hay que decirlo, por fomentar la permanencia del trabajador en situación de activo, ya sea de forma total o parcial. De fondo, y a no olvidar, la necesidad de sostener financieramente nuestro sistema de seguridad social a medio y largo plazo. La fijación de los 67 años como edad futura de jubilación por la Ley 27/2011 constituye sin duda el punto de inflexión en este sentido.

Por su parte, el Real Decreto-ley 5/2013, del 15 de marzo, de medidas para favorecer la continuidad de la vida laboral de los trabajadores

14 En este sentido, López Gandía, Juan, La jubilación parcial tras la reforma de las pensiones, Editorial Bomarzo, 2013, p. 7.

15 De nuevo, López Gandía, Juan, La jubilación parcial..., cit., p. 7. 
Esta revista forma parte del acervo de la Biblioteca Jurídica Virtual del Instituto de Investigaciones Jurídicas de la UNAM

de mayor edad y promover el envejecimiento activo, constituye sin duda el segundo avance significativo en esta renovada estrategia en favor de los empleos de los trabajadores de edad avanzada, iniciada en 2011. Básicamente, el Real Decreto-ley vino a profundizar en la estrategia señalada, ${ }^{16}$ y particularmente en: a) otorgar una mayor relevancia a la cotización del trabajador, lo que se traduce en un incremento de las exigencias de cotización, buscando "favorecer" — así se expresa en la exposición de motivos de la norma, aunque sería más correcto decir "inducir" - la aproximación de la edad real de jubilación a la edad legal de acceso a la jubilación, que, recuerdo, en 2011 había sido ya ampliada; $b$ ) restringir el acceso a la jubilación anticipada sólo a los trabajadores que cuenten con largas carreras de cotización; c) facilitar la compatibilidad entre jubilación y pensión; d) perfeccionar las medidas adoptadas para evitar la discriminación de los trabajadores de más edad en los despidos colectivos, sobre todo las aportaciones que las empresas con beneficios económicos tienen que realizar al tesoro público cuando se procede al despido de trabajadores de cincuenta o más años.

Por último, hay que hacer referencia, aunque sea someramente, al Programa de Activación para el Empleo, aprobado por el Real Decretoley 16/2014, del 19 de diciembre, y que tiene su origen en el acuerdo firmado en el marco del diálogo social por el gobierno, patronal, y sindicatos, el 15 de diciembre de $2014 .{ }^{17}$ Siendo un Programa cuyo pacto parte del compromiso adquirido por todas las partes en un acuerdo anterior, en concreto, el "Acuerdo de propuestas para la negociación tripartita para fortalecer el crecimiento económico y el empleo", del 29 de julio de 2014, en el que se contemplaba que los mayores de 45 años fueran objeto de atención especial, lo cierto es que finalmente los destinatarios del mismo son, de forma genérica, las "personas desempleadas de larga duración" que cumplan ciertos requisitos (artículo lo., Real Decreto-ley, 16/2014). Con todo, y a los efectos que aquí interesan, el Programa prevé la com-

16 Al tiempo que cumplir con la Recomendación del Consejo, del 10 de julio de 2012, sobre el Programa Nacional de Reformas de 2012 de España, y por la que se emite un dictamen del Consejo sobre el Programa de Estabilidad de España para 2012-2015, en cuanto a la sostenibilidad del sistema de pensiones y el impulso del envejecimiento activo.

17 El Programa de Activación tuvo en cuenta las recomendaciones específicas del Consejo de la Unión Europea del 8 de julio de 2014, relativas al Programa Nacional de Reformas de 2014 en España. 
Esta revista forma parte del acervo de la Biblioteca Jurídica Virtual del Instituto de Investigaciones Jurídicas de la UNAM

binación de actuaciones en materia de intermediación laboral, que busca incrementar las posibilidades del desempleado de larga duración - con frecuencia trabajador de edad avanzada - con una ayuda económica de acompañamiento, que resulta compatible, por cinco meses, con el trabajo por cuenta ajena.

Ahora bien, ¿cuál es el papel otorgado a la negociación colectiva en todo este asunto? Con independencia de lo que comentaré en el epígrafe III, tras aproximarme al conocimiento de la acción legislativa francesa, me interesa en estos momentos destacar los siguientes aspectos:

a) Si bien el mencionado ASE 2011 incluía un acuerdo bipartito entre las organizaciones sindicales y empresariales sobre criterios básicos para la reforma de la negociación colectiva, finalmente el gobierno, ante la falta de consenso entre patronal y sindicatos sobre un acuerdo que concretara la reforma, optó por realizar "su" reforma, mediante el Real Decreto-ley 7/2011, del 10 de junio, de medidas urgentes para la reforma de la negociación colectiva. Esta reforma, unida a la impulsada por el Real Decreto-ley 3/2012, del 10 de febrero, de medidas urgentes para la reforma del mercado laboral, termina por conformar un régimen jurídico de la negociación colectiva desconocido hasta el momento.

Estas reformas legales, como sabemos, han dibujado un nuevo escenario de la negociación colectiva de nuestro país, apostándose por la prioridad aplicativa del convenio de empresa de forma notable, en detrimento de la negociación colectiva de sector, particularmente la de carácter provincial. Evidentemente esta novedad no es inocua a los efectos que aquí interesan, aunque sólo sea porque la prioridad aplicativa mencionada relativiza, por ejemplo, los acuerdos que, en sede supraempresarial, puedan alcanzarse en materia de sostenimiento del empleo de los trabajadores de edad avanzada. ${ }^{18}$

Por otra parte, ha de recordarse que es precisamente con ocasión del indicado Real Decreto-ley 3/2012 cuando el legislador introduce en el artículo 51.2 del Estatuto de los Trabajadores (ET) una referencia con-

18 Téngase en cuenta que, tal y como dispone el artículo 84.2, ET, cuestiones muy vinculadas con el puesto de trabajo y su adaptación, como el salario, la retribución de las hora extras, el tiempo de trabajo, el sistema de clasificación profesional o las modalidades de contratación, puede negociarse en cualquier momento por convenio colectivo de empresa, y serán de preferente aplicación. 
Esta revista forma parte del acervo de la Biblioteca Jurídica Virtual del Instituto de Investigaciones Jurídicas de la UNAM

creta a que la consulta en el marco de un procedimiento de despido colectivo "deberá versar, como mínimo, sobre las posibilidades de evitar o reducir los despidos colectivos y de atenuar sus consecuencias mediante el recurso a medidas sociales de acompañamiento, tales como medidas de recolocación o acciones de formación o reciclaje profesional para la mejora de la empleabilidad". Como se puede comprobar, la llamada de atención legislativa es sólo eso, no teniendo necesariamente el acuerdo colectivo que se alcance, en su caso, integrar como contenido mínimo las señaladas medidas sociales de acompañamiento. Con todo, supone una manifestación interesante de la preocupación del legislador por esta cuestión, aunque no debemos olvidar que, por un lado, en ningún momento la norma menciona que los destinatarios de estas medidas tengan que ser necesaria y preferentemente los trabajadores de edad avanzada, y por otro, ha de tenerse en cuenta que el principal freno a la pérdida de empleos por este colectivo de trabajadores a día de hoy la legislación vigente lo fía sobre todo a las medidas de tipo crematístico, perfeccionadas, como hemos señalado, por el Real Decreto-ley 5/2013, y que fundamentalmente obligan a las empresas con beneficios a realizar aportaciones al tesoro público cuando procedan a despedir trabajadores de cincuenta o más años. ${ }^{19}$ A no olvidar tampoco la bonificación de cuotas de las empresas de la seguridad social por el mantenimiento del empleo de trabajadores de más de 59 años.

No obstante, ese mismo Real Decreto-ley introdujo, para el caso de las empresas que procedan a despidos colectivos de más de cincuenta trabajadores, con independencia de su edad - no es por tanto una medida orientada específicamente a los trabajadores de mayor edad, aunque en la práctica pueda ser el caso - la obligación de "ofrecer a los trabajadores afectados un plan de recolocación externa a través de empresas de recolocación autorizadas". ${ }^{20}$ Aunque en principio del tenor de la norma no cabe deducir una obligación de negociar dicho plan - establece que se trata de una oferta-, la lógica indica que ello será así en muchos casos. ${ }^{21}$

\footnotetext{
19 Artículo 51.11, ET.

20 Artículo 51.10, ET.

21 El artículo 9o. del Real Decreto 1483/2012, del 29 de octubre, por el que se aprueba el Reglamento de los procedimientos de despido colectivo y de suspensión de contratos y reducción de jornada, establece un contenido mínimo del plan, concretado en medidas en materia de: a) intermediación, consistentes en la puesta en contacto de las ofertas de
} 
Esta revista forma parte del acervo de la Biblioteca Jurídica Virtual del Instituto de Investigaciones Jurídicas de la UNAM

Cuestión distinta es que el plan no garantiza la recolocación, sino que pretende mejorar la cualificación del trabajador para estar en disposición de ser contratado, al tiempo que por empresas especializadas se le asesora en la búsqueda de empleo, y que por supuesto esta previsión legal, como se constata, tiene por destinatario a un sector pequeño del tejido empresarial español, las empresas medianas y grandes.

b) La Estrategia Global para el Empleo de los Trabajadores y las Trabajadoras de Más Edad 2012-2014 (Estrategia 55 y más), establecida por el gobierno español para orientar sobre todo la acción de las administraciones públicas, y la última por cierto centrada exclusivamente en los problemas de empleo del colectivo que nos ocupa ${ }^{22}$ realiza una aproximación crítica al papel de la negociación colectiva en relación con el empleo de los trabajadores de edad avanzada. Así, y desde una perspectiva negativa, plantea: i) por un lado, en relación con las cláusulas de los convenios colectivos que fijen edades de jubilación forzosa — posibilidad

trabajo existentes en otras empresas con los trabajadores afectados por el despido colectivo; $b$ ) orientación profesional, destinadas a la identificación del perfil profesional de los trabajadores para la cobertura de puestos de trabajo en las posibles empresas destinatarias de la recolocación; c) de formación profesional, dirigidas a la capacitación de los trabajadores para el desempeño de las actividades laborales en dichas empresas; $d$ ) de atención personalizada, destinadas al asesoramiento de los trabajadores respecto de todos los aspectos relacionados con su recolocación, en especial respecto de la búsqueda activa de empleo por parte de los mismos. No obstante, la norma es clara, en el sentido de establecer que el plan de recolocación "podrá ser concretado o ampliado a lo largo del periodo de consultas", por tanto en función de la negociación que se establezca en el periodo de consultas, aunque, ante la posibilidad de que no se llegue a acuerdo, la norma precisa que "al finalizar el mismo [el periodo de consultas] deberá ser presentada su redacción definitiva”, se entiende que por la empresa.

22 Recuérdese que esta Estrategia se acompasa en el tiempo con la Estrategia española de empleo 2012-2014, aprobada por el Real Decreto 1542/2011, del 31 de octubre, hoy día, sustituida por la Estrategia Española de Activación para el Empleo 2014-2016, aprobada ésta por Real Decreto 751/2014, del 5 de septiembre. La Estrategia 20142016 aspira a cambiar el modelo de políticas activas de empleo pasando de un modelo de financiación y gestión que se articula en torno a programas establecidos centralizadamente, "a un nuevo marco acorde con las competencias de las comunidades autónomas en políticas activas en el marco de la unidad de mercado, basado en la evaluación". La cuestión es que, en principio, dicha Estrategia, aunque señala los trabajadores mayores de 55 años como uno de los "colectivos especialmente afectados por el desempleo", no se contempla en forma diferenciada y singular un tratamiento de los problemas de este colectivo en sintonía con las políticas europeas de prolongación de la vida activa de los trabajadores, como sí ha ocurrido en el periodo 2012-2014. 
Esta revista forma parte del acervo de la Biblioteca Jurídica Virtual del Instituto de Investigaciones Jurídicas de la UNAM

como sabemos hoy día eliminada con consecuencia de lo establecido por la D. F. 4a. Dos de la Ley 3/2012, del 6 de julio, de medidas urgentes para la reforma del mercado laboral - sugiere que los interlocutores sociales "analicen conjuntamente la legalidad, acierto y oportunidad de mantener ese tipo de cláusulas en los convenios colectivos", sin ir en esa fecha más allá, conociendo la resistencia de dichos interlocutores a prescindir de esta herramienta de rejuvenecimiento de las plantillas; ii) por otro lado, por lo que respecta a los posibles pactos de competencia e incompatibilidad para después de extinguido el contrato de trabajo, y que en ocasiones son objeto de pacto colectivo, integrando el expediente de regulación de empleo, plantea el que se estudie la prohibición de tales cláusulas, en la medida en que vayan más allá de lo previsto por el artículo 21.2, ET - algo que por cierto no se ha hecho finalmente-

Desde una perspectiva positiva, a su vez, los espacios donde principalmente contempla la actuación negociada son: i) la formación a lo largo de la vida laboral, y en particular el diseño de planes de formación específicos, que al decir del plan "asegure e incremente sustancialmente el número de personas de más edad que reciben formación"; ii) el establecimiento mediante pacto o acuerdo colectivo del derecho a la reducción de jornada de los trabajadores a partir de una determinada edad, con independencia de lo que se pueda establecer al respecto, también, en sede legislativa; iii) en el ámbito de la empresa, "y en el marco de las condiciones de trabajo" - por tanto en muchos casos de forma negociadase sugiere la adopción de medidas que permitan el desarrollo de nuevas competencias y destrezas en el trabajo, mediante la rotación de tareas o el enriquecimiento del puesto, estrategias organizativas que adapten los ritmos, descansos, turnos y horarios de trabajo a las condiciones físicas del trabajador mayor y que aborden el cambio de actividad de los mismos, y el establecimiento de programas que posibiliten los conocimientos teóricos a nivel profesional; iv) la adopción de medidas de movilidad funcional dirigidas a la adaptación del puesto de trabajo con el fin de garantizar la seguridad y salud de los trabajadores. ${ }^{23}$

23 Además, y en relación con lo que se define como la "sensibilización social de los valores positivos del trabajo de los trabajadores y las trabajadoras de más edad", se plantea: a) que el Consejo Estatal de Responsabilidad Social de las Empresas, además de difundir las mejores prácticas, valore introducir, como premisa para que una empresa sea recono- 
Esta revista forma parte del acervo de la Biblioteca Jurídica Virtual del Instituto de Investigaciones Jurídicas de la UNAM www.juridicas.unam.mx

DOI: http://dx.doi.org/10.22201/iij.24484873e.2017.149.11354

\section{La experiencia francesa}

Tal y como en más de un caso se ha señalado, fue la reforma de las pensiones de seguridad social, operada por la Ley 2003-775, del 21 de agosto, de reforma de las pensiones, la que impulsó a los interlocutores sociales, a nivel nacional, a aprovechar los efectos de dicha reforma para iniciar un proceso de diálogo social sobre el empleo de los trabajadores de edad avanzada - seniors como se les denomina en Francia —. ${ }^{24}$ De tal manera que, poco tiempo después, en 2005, fue como vio la luz el Acuerdo Nacional Interprofesional relativo al empleo de los seniors, a fin de promover su mantenimiento y su retorno al empleo, del 13 de octubre (ANI 2005). Si la reforma legal de 2003 implicó el abandono por parte del gobierno de Francia de las políticas seguidas desde los años setenta favorables a la renovación del mercado laboral francés ${ }^{25}$ de tal forma que mediante distintas técnicas jurídicas se inducía o favorecía la incorporación

cida como socialmente responsable, la adopción de medidas dirigidas a garantizar una adecuada gestión del empleo de los trabajadores de más edad; b) que se estudien fórmulas que, respetando la Ley de Contratos del Sector Público, permitan que las condiciones de ejecución de los contratos contribuyan al mantenimiento en el empleo de los trabajadores y trabajadoras de más edad.

24 Martin, Philippe, "La política laboral francesa a favor de los trabajadores de edad madura: fomento y protección del empleo", en Cabeza Pereiro, Jaime et al. (dirs.), La relevancia de la edad en la relación laboral y de seguridad social, Madrid, Aranzadi-ThomsonReuters, 2009, p. 334. En un claro ejemplo, por cierto, de reforma contingente muy determinada por la situación socioeconómica del momento, síntoma del que por cierto suelen adolecer las reformas de seguridad social, las laborales también, por no decirlo, de aquél país, también del nuestro. Sobre esta cuestión, véase Quintero Lima, María Gema, Derecho transitorio de seguridad social, Madrid, La Ley, 2006, p. 16. Como ha señalado LyonCaen, Gerard, "Différence de traitement ou discrimination selon l'âge", Droit Social, núm. 12 (monográfico: L'âge en droit social), 2003, p. 1050, hoy en día la edad empieza a tener la consideración de factor de aseguramiento "del equilibrio contable del régimen de pensiones de vejez".

25 Y que había llevado a Francia a alcanzar en 2005 unos porcentajes de actividad en el segmento 55-64 años del 37.8\%, significativamente por debajo de la media Eurostat $-42.5 \%$ - (Martin, Philippe, "La política laboral francesa a favor...", cit., p. 336). Sobre esta cuestión, Pelissier, Jean, "Âge et perte d'emploi", Droit Social, núm. 12 (monográfico: L'âge en droit social), 2003, pp. 1061 y ss. No obstante, en el caso de algunas grandes empresas, la gestión del envejecimiento de las plantillas ha formado parte, desde tiempo atrás, de la política de personal de las mismas. Véase Volkoff, Serge, "Des "politiques du travail" dans les enterprises, pour tenir compte du viellissement (Quelques exemples en France et en Allemagne)", Travail et Emploi, núm. 69, 1996, pp. 71 y ss. 
Esta revista forma parte del acervo de la Biblioteca Jurídica Virtual del Instituto de Investigaciones Jurídicas de la UNAM

de trabajadores jóvenes en detrimento de los seniors, ${ }^{26}$ el ANI 2005 supuso la asunción por los interlocutores sociales del protagonismo que entiendo les corresponde en la solución de este complejo problema, en línea con la mencionada reforma legislativa. ${ }^{27}$

Hay que señalar a tales efectos que el ANI 2005, antes que un acuerdo con vinculabilidad jurídica, constituye un documento de reflexión que intenta sumar a las organizaciones sindicales y empresarios a la causa de la gestión de la edad compatible con la política europea de prolongación de la vida activa. ${ }^{28}$ De tal manera que una vez ejecutada esta labor, es cuando el Acuerdo aborda otros aspectos de interés, como la necesaria coordinación entre los resultados de la concertación social y la acción legislativa en esta materia, o la necesidad de realizar ciertas acciones legislativas — véase el artículo 25 sobre la jubilación progresiva-. En ese sentido, su estructura es un fiel reflejo de lo señalado, pues: $a$ ) en el título I se plantea la necesidad de que las representaciones negociadoras evolucionen a nuevos planteamientos en materia de gestión de la edad de los trabajadores, incorporando nociones como la adaptación de los trabajadores a los puestos, o el abandono de prejuicios como la disminución de

26 No en vano, la reforma de 2003 supuso una apuesta por el reforzamiento de la contributividad del sistema de seguridad social, de tal manera que en lugar de incrementar la cotización se pasa a exigir un mayor esfuerzo contributivo en el tiempo, si bien no se altera la edad legal de jubilación, que continúa en los sesenta años, por lo que la pensión completa exigirá más años de cotización (véase Moreau, Yannik, "La réforme des retraites du 21 août 2003: une étape importante dans un processus de long terme", Droit Social, núm. 11 (monográfico: La réforme des retraites. Loi du 21 août 2003), 2003, pp. 909 y ss.). Además, en esta época se establecen mecanismos que penalizan el recurso a la jubilación anticipada, al tiempo que se implanta una suerte de sistema "bonus-malus", que nos resulta familiar en España, de manera que el trabajador que al cumplir los 65 años continúa trabajando ve incrementada su pensión, poco a poco, hacia el futuro.

27 Sobre los resultados de la concertación social francesa en relación con las políticas de empleo de los trabajadores maduros, puede ser de interés la consulta de Quintero Lima, María Gema, "Discriminación por edad y protección de los seniors (trabajadores maduros) en el derecho social francés", en Mercader Uguina, Jesús R. (dir.), Trabajadores maduros. Un análisis multidisciplinar de la repercusión de la edad en el ámbito social, Valladolid, Lex Nova, 2009, pp. 392 y ss.

28 Como ha señalado Martin, Philippe, "La política laboral francesa a favor...", cit., nota 25, p. 340, el ANI 2005 "no es un acuerdo normativo en el sentido jurídico". No obstante, el artículo 26 del ANI 2005 prevé el compromiso de los distintos sectores profesionales de adaptar la negociación colectiva al cumplimiento de los objetivos del acuerdo, y todo ello en el plazo de seis meses. 
Esta revista forma parte del acervo de la Biblioteca Jurídica Virtual del Instituto de Investigaciones Jurídicas de la UNAM www.juridicas.unam.mx

DOI: http://dx.doi.org/10.22201/iij.24484873e.2017.149.11354

la productividad conforme la edad se incrementa; $b$ ) en el título II se establece la necesidad de asegurar los itinerarios profesionales de los trabajadores seniors, mediante la adopción, entre otros aspectos de una gestión previsora, y por tanto anticipada, tanto de los puestos de trabajo como de las competencias vinculadas a los mismos; ${ }^{29} c$ ) el título III aborda el retorno de los seniors al empleo, destacando la apuesta por el denominado contrato de profesionalización como vector de reinserción al mercado de trabajo, teniendo en cuenta lo dispuesto al efecto por los acuerdos colectivos de sector y de empresa; d) el título IV, por último, atiende a lo que considera debe ser el diseño del final de la carrera profesional del trabajador.

Poco tiempo después de que viera la luz en ANI 2005, la concertación social, en colaboración con el Parlamento francés y el Consejo Económico y Social de Francia, alumbró, el 6 de junio, el denominado Plan Nacional de Acción Concertado para el Empleo de los Seniors (2006-2010), en cuanto continuación de aquél. Pese a que el citado plan, curiosamente, motivó una significativa acción legislativa - planteada expresamente en el mismo - ${ }^{30}$ el balance de la concertación social desarrollada en el periodo 2005-2006 fue claramente desfavorable, pues, por ejemplo, en 2007 sólo dos sectores profesionales habían incorporado a la negociación colectiva los planteamientos contenidos en los documentos antes referenciados, al tiempo que modalidades contractuales especiales como el contrato de

29 En relación con este aspecto, ha de destacarse la dinámica negociadora que generó el ANI 2005, de tal forma que en los meses posteriores, sobre todo en el ámbito de las grandes corporaciones francesas, se suscribieron un número apreciable de acuerdos de empresa en materia de gestión previsora de los puestos de trabajo y de las competencias vinculadas a éstos, que acogían, en última instancia, planteamientos contenidos en dicho acuerdo. Véase AA.VV., Diagnostic sur l'impact de l'Accord National Interprofessionnel sur l'emploi des seniors de 2006, Paris, CFDT, 2007, pp. 9 y ss.

30 Así, se planteaban cuestiones - que fueron plasmadas por las sucesivas leyes de presupuestos de la seguridad social de 2007 y 2008 - como: a) la supresión de la denominada "contribución Delalande" - a pagar por la empresa a la administración francesaen caso de despido de un trabajador de cincuenta o más años; $b$ ) la revisión de los acuerdos sectoriales que posibilitan a los empresarios jubilar de oficio a los trabajadores antes de los 65 años; c) la creación de un contrato de duración determinada de dieciocho meses para los parados mayores de 57 años de edad; $d$ ) la jubilación progresiva de los trabajadores de sesenta años que hayan cumplido 150 trimestres de cotización; e) el incremento del coeficiente de aumento de la pensión — de un 3\% a un 5\% - para trabajadores de más de sesenta años que sigan trabajando; $f$ ) la posibilidad de acumular pensión y salario hasta un máximo del $160 \%$ del salario mínimo legal. 
Esta revista forma parte del acervo de la Biblioteca Jurídica Virtual del Instituto de Investigaciones Jurídicas de la UNAM

duración determinada para los parados de 57 años de edad no terminó de funcionar.

Por ello, ya en 2008 el gobierno de Francia manifestó su voluntad de adoptar medidas más eficaces. ${ }^{31}$ No obstante, no será hasta 2010 cuando tendrá lugar la aprobación de la Ley 2010-1330, del 9 de noviembre, de reforma de las pensiones. A los efectos que aquí interesan, posiblemente la novedad más interesante que plantea esta ley es el retraso de la edad ordinaria de jubilación, al disponerse que la misma progresivamente pase de los 60 a los 62 años - edad ésta a alcanzar en 2018-, al tiempo que se hace un diseño legal del régimen de cotizaciones por el que en adelante la pensión plena de jubilación requerirá normalmente haber cotizado hasta los 65 años, aunque la idea es alcanzar los 67 en 2023 —utilizando con ello una técnica de diferimiento en el tiempo de ciertos efectos legales que también nos es conocida en España por lo que hace a la Ley 27/2011, o el Real Decreto-ley 5/2013-. ${ }^{32}$

El último capítulo de esta historia lo representa el Acuerdo Interprofesional por un nuevo modelo económico y social al servicio de la competitividad de las empresas y el aseguramiento del empleo y de las carreras profesionales de los trabajadores, del 11 de enero de 2013 (ANI 2013), y cuyos aspectos principales fueron elevados a la categoría de ley en virtud de la Ley 2013-504, del 14 de junio, relativa al aseguramiento del empleo.

31 En el fondo, tampoco podemos olvidar la complejidad del fenómeno, y las contradicciones que registraba la acción legislativa francesa, que con la aprobación de la Ley 2003-775 al tiempo que suprimía ciertas disposiciones legales que posibilitaban la jubilación anticipada, las mantenía como un elemento importante de los instrumentos públicos de ayuda a las empresas en reestructuración (en este sentido, Willmann, Christophe, "Promouvoir le «vieillissement actif»: les modestes propositions des partenaries sociaux (ANI du 13 octobre 2005)", Droit Social, núm. 2, 2006, p. 154). Los estudios indicaban que si en 2005 la tasa de empleo de los trabajadores entre 55 y 64 años era del 37.8\%, en 2007 la misma sólo alcanzaba el 40.5\% (véase Martin, Philippe, "La política laboral francesa a favor...", cit., p. 343).

32 La modificación progresiva de la edad de jubilación ordinaria de los sesenta a los 62 años ha generado una importante discusión en Francia, aunque sólo sea porque se trata de una situación jurídica con larga tradición — se remonta a 1945-. No obstante, parece existir bastante consenso en la idea de que esta novedad legal resulta casi imperativa en atención a la presente situación económica francesa - también visto el sostenimiento del sistema de seguridad social francés a medio y largo plazo- (véase Chauchard, Jean-Pierre, "Sur un malentendu tenace: la retraite à 60 ans", Droit Social, núm. 3 [monográfico: La reforme des retraites], 2011 , pp. 244 y ss.). 
Esta revista forma parte del acervo de la Biblioteca Jurídica Virtual del Instituto de Investigaciones Jurídicas de la UNAM www.juridicas.unam.mx

DOI: http://dx.doi.org/10.22201/iij.24484873e.2017.149.11354

Posiblemente el aspecto más destacable, a los efectos que aquí interesan, de este conjunto de medidas emanadas de la concertación social - pese a que la motivación primera de la ley pueda ser de carácter financiero, vinculada a la necesidad de adaptar el régimen financiero del desempleo a una situación económica crítica, y a que no se trata de una concertación concentrada en las necesidades de los trabajadores seniors ${ }^{-33}$ sea precisamente el concepto que se maneja de la "securisation de l'emploi", que a mi juicio supone una aportación interesante desde la perspectiva de la prolongación de la vida activa de los trabajadores, tras años (todo hay que decirlo) de intentar implementar una serie de políticas al respecto que al menos en el caso francés - el caso español tampoco es muy distinto - han tenido unos resultados más que discretos — nada más que hay que mirar la cifras de ocupación de los trabajadores entre 55 y 64 años-.

A tales efectos, hay que hacer notar que, desde la perspectiva francesa, la "securisation de l'emploi", y en concreto su reforzamiento, pasa fundamentalmente, si nos atenemos al documento gubernamental que inspiró la negociación del ANI 2013, por conciliar: ${ }^{34}$ a) la protección y el acompañamiento de los trabajadores, y prioritariamente de aquellos que ven sus empleos amenazados, o registran una fuerte precariedad; $b$ ) los márgenes de adaptación de las empresas para desarrollar o preservar la

33 Véase sobre esta cuestión Willmann, Christophe, "Loi de sécurisation de l'emploi et assurance chômage: l'essentiel et l'accessorie", Droit Social, núm. 10 (monográfico: Loi relative à la sécurisation de l'emploı), 2013, pp. 772 y ss. Willmann, Christophe, "Retraite: mesures d'ajustement ou réforme de fond?", Droit Social, núm. 10 (monográfico: Loi relative à la sécurisation de l'emploi), 2013, p. 771, se muestra crítico con esta circunstancia, y afirma que las reflexiones realizadas en su día con ocasión de la ley de reforma de 2003 siguen plenamente en vigor, pues una verdadera reforma debe abarcar en su integridad todos los aspectos y facetas que integran las políticas de aseguramiento de la vejez. No obstante, debe tenerse en cuenta que, además de la cuestión tratada en el texto principal, la reforma legal de 2013 contempla aspectos como: a) la creación de una cuenta personal que prevenga la penosidad en el trabajo; $b$ ) la consideración a efectos de cotización de los trimestres de interrupción del trabajo como consecuencia de la licencia por maternidad; $c$ ) la validación de los trimestres respecto a los pequeños trabajos a tiempo parcial; $d$ ) el nuevo cálculo de la bonificación de la pensión por hijo; e) la modificación de la base de cotización de los aprendices; $f$ ) o la asimilación de los periodos de formación profesional a los periodos de aseguramiento.

34 Véase el documento de orientación Negociation nationale interprofessionnelle pour une meilleure securisation de l'emploi, del 7 de septiembre de 2012 (wrwremplli.gouv.fr/files/files/Actulités/document_d_orientation.pdff), p. 12. 
Esta revista forma parte del acervo de la Biblioteca Jurídica Virtual del Instituto de Investigaciones Jurídicas de la UNAM

actividad y el empleo, frente a los cambios que se aceleran en un contexto de competencia internacional reforzada, y que son especialmente útiles para superar las crisis coyunturales, y $c$ ) un alto nivel de diálogo social en las empresas y un mayor papel de los trabajadores y de sus representantes, tanto en las acciones de anticipación como en las acciones de adaptación cuando la situación que atraviesa la empresa es difícil.

Teniendo en cuenta lo anterior, el ANI 2013 concentra sus esfuerzos en dos ámbitos distintos, fundamentalmente. ${ }^{35}$ Por un lado, el refuerzo de la información de los trabajadores sobre las perspectivas y las opciones estratégicas de la empresa — abordado en el título II del ANI 2013-, y que lo que pretende es reforzar la dinámica, que cuenta con una cierta tradición en el ordenamiento jurídico francés - de la gestión preventiva del empleo y de sus competencias ("gestion prévisionnelle des emplois et des compétences" [GPEC])- En relación con este ámbito sí conviene advertir que, pese al interés de los interlocutores sociales de aproximar la práctica negociadora de medidas de movilidad interna al proceso de negociación de la gestión anticipada del empleo y de las competencias, lo cierto es que, finalmente la negociación colectiva de acuerdos de movilidad interna se contempla para empresas de menos de trescientos trabajadores, reservando la mencionada GPEC para las empresas medianas y grandes. En definitiva, el diseño que se realiza supone una profundización de las políticas de flexiseguridad asumidas por el ordenamiento jurídico francés hace ya unos años. ${ }^{36}$

Por otro lado, la puesta a disposición de las empresas de distintos medios para promover la adaptación de las mismas ante la aparición de graves dificultades económicas coyunturales que puedan plantearse y mantener el empleo, destacando, a los efectos que aquí interesa, la institución

35 Para un análisis en mayor profundidad, y de conjunto, puede consultarse, entre otros, el trabajo de Martín Puebla, Eduardo, "La flexibilidad interna negociada en una perspectiva de sécurisation de l'emploi", Trabajo y Derecho, núm. 2, 2015, pp. 60 y ss.

36 Antonmattei, Paul-Henri, "L'accord de mobilité interne: il faut l'essayer!", Droit Social, núm. 10 (monográfico: Loi relative à la sécurisation de l'emploi), 2013, pp. 794 y ss. En relación con el ANI 2013, se ha afirmado, por ejemplo, que el mismo pretende desplazar la protección de los trabajadores hacia nuevos escenarios, como el aseguramiento de los itinerarios formativos, al tiempo que se aboga por que la negociación colectiva asuma nuevas funciones en la gestión de la empresa (Lyon-Caen, Antoine y Sachs, Tatiana, "Equivoques et ambitions d'une réforme", Revue de Droit du Travail, marzo, 2013, pp. 162 y ss.). 
Esta revista forma parte del acervo de la Biblioteca Jurídica Virtual del Instituto de Investigaciones Jurídicas de la UNAM

de dos nuevas modalidades de acuerdos colectivos de empresa: ${ }^{37}$ a) los acuerdos colectivos de mantenimiento del empleo, ${ }^{38}$ y que con carácter temporal van a permitir acordar un nuevo equilibrio por lo que respecta a materias como el tiempo de trabajo, el salario o las condiciones de empleo, de tal manera que, a cambio de ciertos sacrificios, se obtiene el beneficio del sostenimiento del empleo; $b$ ) los acuerdos de salvaguarda del empleo, en el marco del procedimiento de despido colectivo - por tanto en empresas de cincuenta o más trabajadores-, y que a fin de cuentas pretenden lo mismo: limitar el impacto de una medida tan drástica como el despido colectivo. ${ }^{39}$ Básicamente, la idea que subyace en relación con estas medidas propuestas es la adopción negociada de medidas defensivas del empleo, que permitan preservar, en todo o al menos en parte, el empleo existente. ${ }^{40}$ Con todo, el diseño legal realizado no está exento de puntos débiles. Me permito apuntar uno, no menor, en estos momentos: todo trabajador que se oponga a los términos de los acuerdos colectivos que se adopten para defender el empleo, y que por lo tanto se niegue a que se le aplique, podrá ser despedido, entendiéndose que dicho despido lo es por causa económica. Como en algún caso ya se ha señalado, resulta muy discutible que la existencia de un acuerdo colectivo, en los términos expuestos, pueda legitimar jurídicamente la ruptura de un contrato de trabajo por causa económica. ${ }^{41}$ Entretanto, la generación de empleo, y la recolocación de trabajadores, deberá esperar.

37 Couturier, Gerard, "Accords de maintien de l'emploi", Droit Social, núm. 10 (monográfico: Loi relative à la sécurisation de l'emploi), 2013, p. 808, quien señala que, en definitiva, estos acuerdos vienen a salvar ciertas rigideces del derecho del trabajo francés (p. 805).

38 Sobre el peculiar carácter de estos acuerdos colectivos véase Legrand, Henri-José, "Les accords collectifs de 'maintien de l'emploi': entre deux 'frontières' de la négociation collective?", Droit Social, núm. 3, 2013, pp. 245 y ss.

39 Couturier, Gerard, "Un nouveau droit des (grands) licenciements collectifs", Droit Social, núm. 10 (monográfico: Loi relative à la sécurisation de l'emploi), 2013, pp. 814 y ss.

40 Couturier, G., "Accords de maintien...", cit., p. 805.

41 Martín Puebla, Eduardo, "La flexibilidad interna negociada...", cit., pp. 67 y 68. 
Esta revista forma parte del acervo de la Biblioteca Jurídica Virtual del Instituto de Investigaciones Jurídicas de la UNAM

\author{
III. LA PROLONGACIÓN DE LA VIDA ACTIVA \\ DEL TRABAJADOR DE EDAD AVANZADA COMO OBJETO \\ DE LA NEGOCIACIÓN COLECTIVA
}

\title{
1. Lecciones que se pueden extraer de la experiencia comparada española y francesa
}

Hasta el momento, he desgranado, de forma un tanto somera, las experiencias española y francesa en relación con la traslación al ámbito jurídico nacional de la política comunitaria sobre prolongación de la vida activa de los trabajadores de edad avanzada. La cuestión es: ¿qué enseñanzas podemos extraer de la comparativa realizada?

1) Aunque en España carecemos de una norma como el artículo L 1 del Code du Travail francés - según el cual todo proyecto de ley del Gobierno que afecte a aspectos laborales y se sitúe en el ámbito de la negociación colectiva nacional e interprofesional deberá ser objeto de una eventual negociación con las organizaciones sindicales y empresariales en el marco de la concertación social - entiendo que la puesta en marcha de políticas públicas en relación con un tema tan complejo como el que nos ocupa exige una acción concertada del Parlamento y de los interlocutores sociales. En España, como hemos podido constatar, esa concertación se ha dado en determinados momentos, pero últimamente se ha abandonado.

2) Pese a que en Francia los resultados hayan sido muy discutibles hasta el punto de que en 2015 la Ley 2013-504 ha sido objeto de lo que se ha dado en denominar un lifting legislativo - ${ }^{42}$ entiendo que la insis-

42 Datos tan pobres, como que el Ministerio de Trabajo francés contabilizara hasta el 15 de marzo de 2015 un total de nueve acuerdos de mantenimiento del empleo, o cero acuerdos colectivos de movilidad interna, llevaron al gobierno francés a plantear la modificación de la mencionada Ley 2013-504 por la Ley 2015-990, del 6 de agosto de 2015 (Ley Macron). La reforma legal se ha centrado en: a) incrementar la posible duración del acuerdo (de dos a cinco años); b) prever la suspensión de su ejecución, y c) replantear el tratamiento jurídico de la negativa del trabajador. Con todo, la doctrina francesa se ha mostrado pesimista, al considerar que, pese a las reformas, persiste impresión de que se sigue estando ante un dispositivo demasiado encorsetado, de acceso difícil, y que finalmente no es recomendable (Antonmattei, Paul-Henri, "Accord de maintien de l'emploi: premier lifting législatif”, Droit Social, núm. 10, 2015, pp. 811 y ss). Véase, igualmente, Porta, Jérôme, "Les accords de maitien de l'emploi ont-ils un avenir?", Revue de Droit du Travail, septiembre, 2015, pp. 499 y ss. 
Esta revista forma parte del acervo de la Biblioteca Jurídica Virtual del Instituto de Investigaciones Jurídicas de la UNAM

tencia francesa en implicar a las distintas unidades negociales, particularmente en los ámbitos sectorial y de empresa, en la puesta en práctica de medidas en favor de la prolongación de la vida activa de los trabajadores seniors, constituye una medida acertada. No es sólo que la negociación colectiva española se caracterice por una escasa imaginación en esta materia, ${ }^{43}$ es que además con frecuencia los interlocutores sociales españoles parecen dar a entender que la prolongación de la vida activa es una cuestión que debe resolverse sobre todo sobre la base de la pura acción del legislador, actuando básicamente sobre la institución jurídica de la jubilación, la cotización, la fijación de incentivos y, últimamente, también, sobre la formación y recualificación de los trabajadores. ${ }^{44}$ Un ejemplo de lo afirmado: aunque el II Acuerdo para el Empleo y la Negociación Colectiva 2012, 2013 y 2014 contempla una serie de pautas, por ejemplo, sobre la adopción negociada de medidas de flexibilidad interna, lo cierto es que el tratamiento de esta cuestión de forma específica - cuando entiendo que debería tener la consideración de política de Estado, sobre todo vista la composición de edad del colectivo de desempleados de este país - , brilla por su ausencia; afirmación similar cabe realizar del más reciente III Acuerdo para el Empleo y la Negociación Colectiva 2015, 2016 y 2017.

3) En España se ha insistido en los últimos años en la necesidad de recualificar al trabajador de edad avanzada para ponerlo en disposición de afrontar nuevos trabajos, insistiendo para ello en la importancia, en línea con los postulados comunitarios, de la formación a lo largo de la vida. En este sentido, y en el marco en concreto de los despidos colectivos, en los últimos tiempos se ha puesto el acento en la importancia de establecer planes de recolocación, como una suerte de salvavidas ante la lastimosa situación en que queda el trabajador relegado al desempleo, en ocasiones, y sobre todo si es un trabajador de edad avanzada, por largo tiempo. Sin embargo, la cruda realidad es que los planes de recolocación no están fun-

43 Elorza Guerrero, Fernando, "La negociación colectiva: análisis de situación", en Elorza Guerrero, Fernando y Fernández Roca, Francisco Javier (coords.), El mantenimiento del empleo por los trabajadores de edad avanzada en Andalucía, Madrid, Marcial Pons, 2012, pp. 151 y ss.

44 En este sentido, ha de destacarse la aprobación en fecha reciente de la Ley 30/2015, del 9 de septiembre, por la que se regula el Sistema de Formación Profesional para el empleo en el ámbito laboral. Sobre la misma véase la reflexión que se realiza en el apartado $\mathrm{V}$ de este trabajo. 
Esta revista forma parte del acervo de la Biblioteca Jurídica Virtual del Instituto de Investigaciones Jurídicas de la UNAM

cionando. ${ }^{45}$ Por ello, tal vez sería más realista asumir que en un mercado de trabajo con muy escasa circulación, como el español, el aseguramiento del empleo debería tener prioridad sobre la recolocación, que finalmente resulta en muchas ocasiones una quimera. La cuestión es que esa defensa del empleo debería articularse en sede de negociación colectiva sobre conceptos conocidos, como la adaptación del puesto del trabajo y de las tareas a las características psicofísicas del trabajador, la formación continuada del mismo, etcétera.

No en vano, considero que la propuesta francesa en torno al concepto de "securisation de l'emploi" debería ser sopesada, al menos en lo que entiendo su dimensión más interesante: aquella que maneja, como se ha señalado en páginas anteriores, los conceptos acompañamiento de los trabajadores en sus necesidades - sobre todo formativas - adaptación de las empresas al mercado y mayor diálogo empresa-representantes de los trabajadores. Ahora bien, en ningún caso, y en esto sí me parece rechazable el planteamiento francés, se puede pretender una defensa del puesto de trabajo sobre la base de una rebaja de los estándares de calidad de las condiciones de trabajo y empleo, por mucho que pueda tratarse de acuerdos colectivos, en principio, temporales (entre dos y cinco años). Parece que está costando, en relación con la materia que nos ocupa, que la frase pronunciada por Hegel en cierta ocasión - "cuando la historia lo necesita, la técnica comparece"- se materialice. ${ }^{46}$

\section{La negociación colectiva intergeneracional como factor de aseguramiento del empleo de los trabajadores de edad avanzada}

He señalado anteriormente que la acción legislativa en relación con la prolongación de la vida activa de los trabajadores requiere de algo más que la adopción de medidas legales que pretenda favorecer la permanencia en activo de los trabajadores de edad avanzada, y que la acción de la

45 Véase el diario El País (17 de marzo de 2013): "El fiasco de los planes de recolocación. Las empresas que despiden cumplen los escasos mínimos legales para reinsertar al trabajador".

46 De esta manera, Alonso Olea, Manuel, "El trabajo como bien escaso", Revista del Ministerio de Trabajo y Asuntos Sociales, núm. 33, 1998, p. 29, expresaba su confianza en la futura solución de un problema que como sabemos es connatural a las sociedades modernas desde hace décadas. 
Esta revista forma parte del acervo de la Biblioteca Jurídica Virtual del Instituto de Investigaciones Jurídicas de la UNAM

negociación colectiva en este ámbito entiendo que resulta fundamental. Ahora bien, considero igualmente que no cualquier dinámica negociadora resulta válida.

En este sentido, entiendo que el futuro de esta cuestión ha de pasar por lo que se ha dado en llamar la negociación intergeneracional, concepto éste que hace referencia a la "integración de políticas y estrategias para los trabajadores jóvenes y mayores a través de la negociación colectiva y el diálogo social". ${ }^{47}$ Sólo desde una consideración conjunta de los intereses y necesidades tanto de los trabajadores jóvenes como de los de edad avanzada resultará posible superar el actual escenario laboral en el que el mantenimiento en activo de los trabajadores viejos se ve como un obstáculo para la incorporación de jóvenes trabajadores, siendo este factor, en muchos casos, el elemento que determina la extinción del contrato de trabajo del trabajador de edad avanzada por la empresa.

En las páginas anteriores, el lector ha podido constatar cómo en el caso francés se ha intentado avanzar en el desarrollo del concepto de aseguramiento del empleo, buscando la complicidad de las organizaciones sindicales, planteamiento que hasta el momento, sin embargo, no se ha visto culminado con el éxito. En el caso español, por su parte, la sinergia entre la acción legislativa y la negociación colectiva en esta materia es prácticamente inexistente, ante el escaso interés que, entre otras cosas, muestran los agentes sociales por la materia, la cual parece que debe ser una cuestión a situar exclusivamente en el ámbito legislativo.

Posiblemente no deba olvidarse que las limitadas experiencias de negociación intergeneracional existentes se explican en parte por la inexistencia de un planteamiento promocional de la misma por parte de la UE, al formular sus políticas sobre prolongación de la vida activa de los trabajadores viejos ha obviado esta importante cuestión. En este sentido, el desarrollo de la mencionada negociación intergeneracional entiendo que debe ser apoyada y promovida desde las instancias comunitarias, al tiempo que desde las instituciones nacionales, como ya he señalado.

47 Rönnmar, Mia, "Intergenerational Bargaining: Towards Integrated Bargaining for Younger and Older Workers in EU countries", en http://intergenerationalbargaining.eu/ uploads/backbone/upload/asset/54/Sweden_R_nnmar_Abstract_iNGenBar_final.pdf, 2014, p. 1, quien señala cómo, en el caso de su país (Suecia), la "redistribución intergeneracional de empleo entre los trabajadores mayores y menores, es ajena a la política pública sueca y negociación colectiva”. 
Esta revista forma parte del acervo de la Biblioteca Jurídica Virtual del Instituto de Investigaciones Jurídicas de la UNAM

En todo caso, considero que el aseguramiento exitoso del empleo de los trabajadores de edad avanzada pasa por el desarrollo de prácticas de negociación intergeneracional que ponga en valor la experiencia y el conocimiento de éstos, en cuanto factor que ha de ser combinado con la aportación positiva que siempre supone la incorporación de los trabajadores jóvenes. De tal forma que en el futuro la acción negociadora debería orientarse a la integración en las estructuras empresariales, de forma combinada, de trabajadores jóvenes y mayores. ${ }^{48} \mathrm{~A}$ tales efectos, la negociación colectiva intersectorial y sectorial debería establecer criterios y servir de motor de impulso de la negociación en ámbitos inferiores. Y ello porque es en el ámbito de la negociación colectiva de empresa donde se deberían concretar las medidas que hagan posible la integración en las mencionadas estructuras empresariales de los trabajadores jóvenes y de edad avanzada.

\section{SOBRE LA NECESIDAD DE UN TRATAMIENTO ESPECÍFICO LEGAL DE LA EDAD AVANZADA COMO FACTOR QUE INCIDE EN EL EMPLEO Y EN LA RELACIÓN DE TRABAJO}

Hasta el momento hemos tenido la oportunidad de constatar la existencia de un conjunto de reformas legislativas en España y Francia que, mediante la adopción de distintas medidas legislativas, pretenden inducir la prolongación de la vida activa de los trabajadores. Igualmente, se ha reflexionado sobre el importante papel que a mi juicio debe desempeñar la negociación colectiva en la puesta en marcha de medidas que posibiliten la mencionada prolongación de la vida activa.

Sin embargo, hay que ser conscientes de que el papel al que considero está llamado a medio y largo plazo la autonomía colectiva en relación con todo este asunto se ve complicado por la inexistencia de un marco legal que favorezca la acción de dicha autonomía en este terreno. Es necesario por tanto desarrollar una acción legislativa que introduzca en el ordena-

48 Un análisis del estado de la cuestión y de las posibilidades de la negociación intergeneracional puede consultarse en Tros, Frank, "Collective bargaining for younger and older workers in times of crisis. An international comparative study on opportunities and barriers in integrated approaches", conference paper, junio, 2015, en http://wrere.researchgate. net/publication/280307295_Collective_bargaining_for_younger_and_older_workers_in_times_of_cri sis._An_international_comparative_study_on_opportunities_and_barriers_in_integrated_approaches. 
Esta revista forma parte del acervo de la Biblioteca Jurídica Virtual del Instituto de Investigaciones Jurídicas de la UNAM

miento jurídico una consideración específica de la edad como factor con incidencia en el empleo y la relación de trabajo, y que permita superar la lógica imperante - tanto en Francia como en España - de la edad "como factor de ajuste del mercado de trabajo", ${ }^{49}$ y la identificación de la edad de jubilación con la "idea de presunción de inhabilidad", entendida ésta como "absoluta incapacidad de proveerse de una renta necesaria para vivir por medio de una actividad laboral". ${ }^{50}$

A los efectos que aquí interesan, y teniendo en cuenta la perspectiva adoptada, sería necesario plantearse que la acción legislativa de los Estados fuera más allá de las reformas legislativas señaladas en páginas anteriores, de manera que desde la ley se promocionara la participación de la negociación colectiva en la materia. En definitiva, entiendo que la promoción de la negociación colectiva intergeneracional requiere de un marco legal que sea favorable al mismo. No sería la primera vez que se adoptan medidas de promoción legal. Un ejemplo no tan lejano lo tenemos en la reforma del Estatuto de los Trabajadores español efectuada en su momento para que la negociación colectiva integrara entre su objeto habitual el establecimiento de medidas en favor de la igualdad en el trabajo, o la realizada para que los convenios colectivos se ocuparan de establecer procedimientos de solución extrajudicial de los conflictos generados en torno a los procesos de negociación, de forma que éstos no terminen siendo fallidos.

En este sentido, y tomando como referente en estos momentos el caso español, sería también importante que la ley dispusiera expresamente la necesidad de que en los procesos de despido colectivo, que generalmente suelen afectar con especial intensidad a los trabajadores de edad avanzada, se incluyera una referencia legal a la necesidad de dialogar durante la negociación de dicho despido con los representantes de los trabajadores, sobre las medidas a adoptar para mejorar la estabilidad en el empleo de los trabajadores de edad avanzada. Es bueno que la ley se ocupe y preocupe de establecer que con ocasión de estos procesos, empresa y repre-

49 Martin, Philippe, "La política laboral francesa a favor...”, cit., p. 335, quien en relación con el caso francés - y recordando a Guillemard, 2003- afirma que "se puede estimar que el sistema de pensión de los trabajadores asalariados, en Francia, deja poca libertad a los individuos y funciona como una «guillotina»".

50 Balandi, Gian Guido, "La edad de jubilación", en Camas Roda, Ferran (coord.), La edad en relación al empleo, la seguridad social y la inmigración, Barcelona, Bosch, 2009, p. 64. 
Esta revista forma parte del acervo de la Biblioteca Jurídica Virtual del Instituto de Investigaciones Jurídicas de la UNAM

sentantes de los trabajadores dialoguen sobre "las posibilidades de evitar o reducir los despidos colectivos y de atenuar sus consecuencias mediante el recurso a medidas sociales de acompañamiento, tales como medidas de recolocación o acciones de formación o reciclaje profesional para la mejora de la empleabilidad" (artículo 51.5 Estatuto de los Trabajadores); pero también sería aconsejable que en ese proceso negociador se aborden las medidas que podrían adoptarse en el marco del diálogo intergeneracional para promover la estabilidad en el empleo de los trabajadores de edad avanzada.

En cualquier caso, también hay que dejar constancia de que en ocasiones las propuestas que se realizan desde la ley a la negociación colectiva no encuentran en ésta el correspondiente eco. Un ejemplo de ello es la norma establecida en el artículo 12.7 e) del Estatuto de los Trabajadores español, que dispone que "en la negociación colectiva se podrán establecer medidas para impulsar la celebración de contratos de relevo". La referencia legal puede ser un buen punto de partida para que la autonomía colectiva se implique en un verdadero diálogo intergeneracional que ordene el acceso a la jubilación parcial anticipada de los trabajadores de edad avanzada, al tiempo que la incorporación de trabajadores más jóvenes, o que tenían una débil vinculación con la empresa - por ejemplo, mediante un contrato de pocas horas-, a la misma. Como ya se ha señalado anteriormente, si uno analiza la negociación colectiva española de estos años comprobará que las cláusulas convencionales en relación con este asunto son muy escasas. Sin duda la patronal española y las organizaciones sindicales tienen un largo camino que recorrer en esta materia, y los acuerdos sobre promoción de la negociación colectiva que periódicamente se alcanzan en este país puede ser un buen punto de comienzo para animar a los negociadores, sobre todo en el ámbito de la empresa, a abordar este importante asunto.

\section{REFLEXIÓN FINAL}

La prolongación de la vida activa de los trabajadores de edad avanzada no es una cuestión fácil de resolver, como es conocido, y constituye una problemática que aqueja no sólo a los mercados laborales europeos; de ahí la importancia de los análisis comparados que puedan realizarse con relación a la práctica que se está desarrollando al respecto en los distintos países. En 
Esta revista forma parte del acervo de la Biblioteca Jurídica Virtual del Instituto de Investigaciones Jurídicas de la UNAM

el caso de España y Francia, convendría retener el interés de un concepto, como el mencionado de "securistion de l'emploi", cuya ejecución, sin embargo, entiendo que resulta altamente criticable, toda vez que no parece razonable asumir que el mencionado aseguramiento del empleo tenga que pasar necesariamente por una reducción de la calidad de la condiciones de trabajo y empleo de los trabajadores de edad avanzada.

Entiendo que el futuro pasa, como se ha señalado en páginas anteriores, por la combinación de cuatro aspectos esenciales de distinta naturaleza, como son: a) una mayor implicación de la autonomía colectiva en la adopción de medidas que posibiliten la prolongación de la vida activa de los trabajadores - con un mayor protagonismo del diálogo social entre patronal y sindicatos y de éstos con el Estado-- para lo que será necesario desarrollar procesos de negociación colectiva multinivel, sobre todo en el ámbito sectorial o intersectorial, así como de empresa; $b$ ) el desarrollo de procesos de negociación colectiva intergeneracional, que integre la actividad de los trabajadores maduros y jóvenes en las empresas, abordando la misma desde el convencimiento de que ambos colectivos pueden aportar valores positivos a la actividad empresarial; c) un tratamiento específico, en el plano legal, de la edad avanzada, como factor que incide en el empleo y en la relación de trabajo, que promueva la implicación de la autonomía colectiva en la adopción de medidas que posibiliten la prolongación de la vida activa de los trabajadores de edad avanzada en el marco de la negociación colectiva intergeneracional señalada; d) una clara apuesta por la formación de los trabajadores como fórmula de garantía de su estabilidad en el empleo, y factor que constituya el fundamento del mantenimiento de sus condiciones de trabajo y empleo, revalorizando con ello el perfil y aptitudes de los mismos.

En relación con este último aspecto, merece destacarse cómo España, en fechas recientes, ha procedido a la completa remodelación del régimen jurídico del sistema de formación profesional para el empleo en el ámbito laboral, mediante la promulgación de la Ley 30/2015, del 9 de septiembre. Aunque en el origen de la norma está la voluntad del gobierno español de abordar una reforma del régimen de la formación profesional para el empleo que atajara los sucesivos escándalos acaecidos en los últimos años en relación con la gestión de los fondos destinados a estos fines, lo cierto es que al dictado de la misma se ha implantado en este país la co- 
Esta revista forma parte del acervo de la Biblioteca Jurídica Virtual del Instituto de Investigaciones Jurídicas de la UNAM

nocida como "cuenta de formación", en cuanto registro que, según señala la propia exposición de motivos de la norma, "acompañará al trabajador a lo largo de su carrera profesional al objeto de acreditar su historial formativo y de orientar la oferta formativa al incremento de su empleabilidad”. Dicha cuenta se asociará al número de afiliación a la seguridad social española, y en la misma se inscribirá "la formación recibida por el trabajador a lo largo de su carrera profesional, y en todo caso la recibida de acuerdo con el Catálogo Nacional de Cualificaciones Profesionales y el Marco Español de Cualificaciones para la Educación Superior" (artículo 20.2 de la Ley 30/2015).

El planteamiento no es exclusivo de este país, y tiene como antecedente más inmediato precisamente la ley francesa 2013-504, del 14 de junio, relativa al aseguramiento del empleo, ${ }^{51}$ que consagra para el caso francés la denominada "cuenta personal de formación", y que constituye el último desarrollo galo en materia de formación, y que entronca con los planteamientos que comenzaron a realizarse en dicho país, allá por 1999, en relación con la necesidad de reconocer jurídicamente el derecho a la formación individual..$^{52}$ No pretendo en estos momentos realizar un análisis en profundidad del régimen jurídico en la materia, pero sí creo necesario subrayar cómo la ley francesa de 2013 constituye la expresión de la voluntad de aquel país de reconocer la importancia de la formación a lo largo de la vida como un derecho individual de "cualquier personal,

51 Norma que, en materia de formación, ha sido objeto de reforma posteriormente por la Ley 2014-288, del 5 de marzo, relativa a la formación profesional, al empleo y a la democracia social, y que ha realizado distintos ajustes en la normativa promulgada en 2013 en la materia.

52 Cabe recordar cómo en dicho año el gobierno francés elaboró un documento (Péry, Nicole, La formation professionnll. Diagnostics, défis et enjeux, 17 de marzo de 1999, documento de la Secretaría de Estado para los derechos de la mujer y la formación profesional) en el que ya entonces se puso de manifiesto la necesidad de reconocer el derecho a la formación individual, en cuanto derecho que debería ser susceptible de transferencia - por lo tanto, el derecho a la formación que se hubiera adquirido no desaparecerían con la movilidad del trabajador a otra empresa - y garantizado colectivamente - para lo que se planteaba una redistribución de los fondos de formación-. No será sin embargo hasta el Acuerdo Nacional Interprofesional, del 11 de enero de 2008, sobre la modernización del mercado de trabajo (ANI 2008), y la posterior Ley 2009-1437, del 24 de noviembre, relativa a la orientación y formación profesional a lo largo de la vida, cuando se consagre en el ordenamiento jurídico francés la portabilidad de los derechos de formación no utilizados, de una empresa a otra. 
Esta revista forma parte del acervo de la Biblioteca Jurídica Virtual del Instituto de Investigaciones Jurídicas de la UNAM

independientemente de su estatus, a partir de su ingreso en el mercado de trabajo" (artículo 5 de la Ley 2013-504), superando con ello lo que se ha dado en denominar "la lógica del puesto de trabajo". ${ }^{53}$ En una línea parecida se sitúa la ley española.

En cualquier caso, y con independencia de los interrogantes que suscitan una y otra norma cuando se analizan las mismas en profundidad, ${ }^{54}$ entiendo que la acción legislativa desplegada en ambos países en estos últimos años constituyen el inicio de una senda que supone, en definitiva, el reconocimiento de la importancia de la formación en cuanto factor clave en la prolongación de la vida activa del trabajador, y como tal un derecho que debe acompañar, y poder ejercerse, por el trabajador con independencia de la situación en que se encuentre en cada momento en el mercado de trabajo. En este sentido, la formación ha de configurarse - y así parece asumirse legislativamente en ambos países - en el vector principal de la mejora de la empleabilidad de todo trabajador, no sólo de cara a poder optar a otros puestos de trabajo en caso de perder el propio, sino también como mecanismo de garantía del empleo en la propia empresa. No obstante, hay que ser conscientes de que el enfoque apuntado del derecho individual a la formación se encuentra todavía en fase de maduración, por lo que a medio plazo es razonable esperar posteriores ajustes legislativos que permitan perfeccionar la normativa vigente en uno y otro país.

\section{BIBLIOGRAFíA}

Alonso OleA, Manuel, "El trabajo como bien escaso", Revista del Ministerio de Trabajo y Asuntos Sociales, núm. 33, 1998.

53 Maggi-Germain, Nicole, "El papel de la formación profesional continua en la Ley sobre la sécurisation de l'emploi de 14 de junio de 2013: la cuenta personal de formación”, Revista Internacional y Comparada de Relaciones Laborales y Derecho del Empleo, vol. 2, núm. 1, enero-marzo, 2014, p. 113.

54 Maggi-Germain, Nicole, "El papel de la formación profesional continua...", cit., nota 52, p. 118, por ejemplo, se pregunta hasta qué punto el nuevo desarrollo normativo francés contribuye a asegurar las trayectorias profesionales de los trabajadores, desarrollando sus capacidades profesionales, y no supone finalmente una operación para responsabilizar al trabajador de su propio proceso formativo haciendo recaer sobre él peso de su "empleabilidad". Estas dudas también pueden suscitarse si se analiza la norma española. 
Esta revista forma parte del acervo de la Biblioteca Jurídica Virtual del Instituto de Investigaciones Jurídicas de la UNAM

AntonmatTei, Paul-Henri, "L'accord de mobilité interne: il faut l'essayer!", Droit Social, núm. 10 (monográfico: Loi relative à la sécurisation de l'emploi), 2013. Social, núm. 10, 2015.

AA.VV., Diagnostic sur l'impact de l'Accord National Interprofessionnel sur l'emploi des seniors de 2006, París, CFDT, 2007.

BALANDI, Gian Guido, "La edad de jubilación", en CAMAS RODA, Ferran (coord.), La edad en relación al empleo, la seguridad social y la inmigración, Barcelona, Bosch, 2009.

Chauchard, Jean-Pierre, "Sur un malentendu tenace: la retraite à 60 ans", Droit Social, núm. 3 (monográfico: La reforme des retraites), 2011.

COURSIER, Philippe, "La réforme française des retraites et l'Union européene", Droit Social, núm. 11 (monográfico: La réforme des retraites. Loi du 21 août 2003).

Couturier, Gerard, "Accords de maintien de l'emploi", Droit Social, núm. 10 (monográfico: Loi relative à la sécurisation de l'emploi), 2013. , "Un nouveau droit des (grands) licenciements collectifs", Droit Social, núm. 10 (monográfico: Loi relative à la sécurisation de l'emploi), 2013. Desbarats, Isabelle y Esteban LegarReta, Ricardo, "Dispositivos de protección social que incentivan el mantenimiento en actividad de los trabajadores maduros: una tendencia análoga en Francia y España”, en AA.VV., La protección del empleo de los trabajadores de edad: una perspectiva franco-española, Valencia, Tirant lo Blanch, 2013.

Elorza Guerrero, Fernando, "La negociación colectiva: análisis de situación", en ElORZA GUERRERO, Fernando y FERnÁndez RoCA, Francisco Javier (coords.), El mantenimiento del empleo por los trabajadores de edad avanzada en Andalucía, Madrid, Marcial Pons, 2012.

LEGRAND, Henri-José, "Les accords collectifs de 'maintien de l'emploi': entre deux 'frontières' de la négociation collective?", Droit Social, núm. 3, 2013.

LÓPEZ GANDÍA, Juan, La jubilación parcial tras la reforma de las pensiones, Albacete, Editorial Bomarzo, 2013.

Lyon-Caen, Antoine y Sachs, Tatiana, "Equivoques et ambitions d'une réforme", Revue de Droit du Travail, marzo de 2013.

LyON-GaEN, Gerard, "Différence de traitement ou discrimination selon l'âge”, Droit Social, núm. 12 (monográfico: L'âge en droit social), 2003. 
Esta revista forma parte del acervo de la Biblioteca Jurídica Virtual del Instituto de Investigaciones Jurídicas de la UNAM

MAGGi-GERMAin, Nicole, "El papel de la formación profesional continua en la Ley sobre la sécurisation de l'emploi de 14 de junio de 2013: la cuenta personal de formación", Revista Internacional y Comparada de Relaciones Laborales y Derecho del Empleo, vol. 2, núm. 1, enero-marzo, 2014.

MARTIN, Philippe, "La política laboral francesa a favor de los trabajadores de edad madura: fomento y protección del empleo", en CABEZA PEREIRO, Jaime et al. (dirs.), La relevancia de la edad en la relación laboral y de seguridad social, Madrid, Aranzadi-Thomson-Reuters, 2009.

MARTín Puebla, Eduardo, "La flexibilidad interna negociada en una perspectiva de sécurisation de l'emploi", Trabajo y Derecho, núm. 2, 2015. MOREAU, Yannik, "La réforme des retraites du 21 août 2003: une étape importante dans un processus de long terme", Droit Social, núm. 11 (monográfico: La réforme des retraites. Loi du 21 août 2003), 2003.

PANizo Robles, José Antonio, "Dos décadas de reformas de la seguridad social: del Pacto de Toledo de 1995 al Acuerdo Social y Económico de 2011 ", Revista de Trabajo y Seguridad Social, CEF, núm. 336, 2011.

Pelissier, Jean, “Âge et perte d'emploi”, Droit Social, núm. 12 (monográfico: L'âge en droit social), 2003.

PORTA, Jérôme, "Les accords de maitien de l'emploi ont-ils un avenir?", Revue de Droit du Travail, septiembre, 2015.

QUintero Lima, María Gema, Derecho transitorio de seguridad social, Madrid, La Ley, 2006.

, "Discriminación por edad y protección de lo seniors (trabajadores maduros) en el derecho social francés", en MERCADER UGUINA, Jesús R. (dir.), Trabajadores maduros. Un análisis multidisciplinar de la repercusión de la edad en el ámbito social, Valladolid, Lex Nova, 2009.

RÖNNMAR, Mia, "Intergenerational Bargaining: Towards Integrated Bargaining for Younger and Older Workers in EU Countries", en http:// intergenerationalbargaining.eu/uploads/backbone/upload/asset/54/Sweden_R_nnmar_ Abstract_iNGenBar_final.pdf, 2014.

TORTUero PlazA, José Luis, La reforma de la jubilación. (Marco de referencia y Ley 27/2011, de 1 de agosto, sobre Actualización, Adecuación y Modernización del Sistema de la seguridad social), Madrid, Thomson-Reuters, 2011.

Tros, Frank, "Collective Bargaining for Younger and Older Workers in Times of Crisis. An International Comparative Study on Opportunities and Barriers in Integrated Approaches", Conference paper, junio de 2015, en http://wrere.researchgate.net/publication/280307295_Collective_ 
bargaining_for_younger_and_older_workers_in_times_of_crisis._An_internatio nal_comparative_study_on_opportunities_and_barriers_in_integrated_approaches. VOLKOFF, Serge, 'Des 'politiques du travail' dans les enterprises, pour tenir compte du viellissement (Quelques exemples en France et en Allemagne)", Travail et Emploi, núm. 69, 1996.

Willmann, Christophe, "Promouvoir le «vieillissement actif»: les modestes propositions des partenaries sociaux (ANI du 13 octobre 2005)", Droit Social, núm. 2, 2006.

-, "Loi de sécurisation de l'emploi et assurance chômage: l'essentiel et l'accessorie", Droit Social, núm. 10 (monográfico: Loi relative à la sécurisation de l'emploi), 2013.

, "Retraite: mesures d'ajustement ou réforme de fond?", Droit Social, núm. 10 (monográfico: Loi relative à la sécurisation de l'emploi), 2013. 